\title{
A LEI DA FICHA LIMPA ENTRE O DISCURSO DA MORALIDADE E OS INTERESSES DOS CONGRESSISTAS: UMA ANÁLISE DA APROVAÇÃO DA LEI COMPLEMENTAR N. 135/2010 A PARTIR DA TEORIA DA ESCOLHA RACIONAL
}

\author{
The Clean Record Law between the speech of morality and the interests \\ of congressmen: an analysis of the approval of Complementary Law $n$. \\ 135/2010 from view of the theory of rational choice
}

\section{Luiz Eduardo Peccinin \\ Lygia Maria Copi}

Resumo: Chamada de iniciativa popular, a chamada "Lei da Ficha Limpa" - Lei Complementar n. 135/2010 - incrementou substancialmente o sistema de inelegibilidades já existente na Lei Complementar $n^{\circ} 64 / 1990$. O presente artigo tem como objetivo analisar o processo de sua aprovação no Congresso Nacional com fundamento na teoria da escolha racional aplicada à Ciência Política, a fim de compreender o comportamento e os interesses dos atores políticos envolvidos. Especificamente, a proposta é de verificar, através de manifestações públicas dos congressistas, o que motivou a aprovação da Lei: a busca pela suposta moralidade política ou a sua reeleição. Mediante uma metodologia fundada na revisão bibliográfica da doutrina especializada no tema, bem como em notícias da imprensa acerca do assunto à época dos fatos, faz-se um estudo desse processo pelas lentes do institucionalismo racional. Para além de analisar o processo de aprovação desta lei específica, o artigo contribui por demonstrar os interesses em jogo nas arenas do processo legislativo como um todo.

Palavras-chave: Inelegibilidade. Ficha Limpa. Escolha racional. Institucionalismo.
Abstract: Called a popular initiative, the so-called "Clean Record Law" - Complementary Law n. 135/2010 - substantially increased the existing ineligibility system in Complementary Law n. 64/1990. This article aims to analyze the process of its approval in the National Congress based on the theory of rational choice applied to Political Science, in order to understand the behavior and interests of the political actors involved. Specifically, the proposal is to verify, through public manifestation of congressmen, what motivated the approval of the Law: the search for the supposed political morality or their reelection. Through a methodology based on the bibliographical revision of the doctrine specialized in the subject, as well as the press news about the subject at the time of the facts, a study of this process is made through the lens of rational institutionalism. In addition to analyzing the process of passing this specific law, the article contributes by demonstrating the interests at stake in the arenas of the legislative process as a whole.

Keywords: Ineligibility. Clean sheet. Rational choice. Institutionalism.

Artigo recebido em 3 set. 2019 e aprovado em 11 out. 2019. 


\section{Considerações iniciais}

Divulgada como de iniciativa popular", a assim conhecida "Lei da Ficha Limpa" - Lei Complementar nº 135/2010 - acresceu hipóteses de inelegibilidade dentre as já previstas pela redação original da Lei Complementar n.ำ6/1990: arrolou mais crimes cuja condenação atrai a impossibilidade de candidatura ${ }^{2}$, previu a criação de diversos novos casos de incidências anteriormente não previstos e a ampliação dos prazos de modo geral e uniforme, de três para oito anos. A principal novidade da LC n- ${ }^{\circ}$ 135/2010, todavia, foi a suficiência de uma condenação "proferida por órgão judicial colegiado" sem necessidade de trânsito em julgado para a incidência da condição de inelegível.

Logo após o início de sua vigência, o Supremo Tribunal Federal julgou as Ações Declaratórias de Constitucionalidade n. ${ }^{2} 2$ e 30 e a Ação Direta de Inconstitucionalidade n.o 4.578, estabelecendo, por apertada maioria, a constitucionalidade da $\mathrm{LC} \mathrm{n}{ }^{-0}$ 135/3010, especialmente da antecipação da inelegibilidade ao trânsito em julgado da sentença condenatória em face da garantia do art. 5o, LVII, da Constituição ${ }^{3}$, bem como de sua retroatividade a fatos pretéritos a sua entrada em vigor ${ }^{4}$, a despeito da regra da anualidade do artigo 16 da Carta $^{5}$.

\footnotetext{
1 "Propagandeada" pois, ao final, foi apresentada como Subemenda Substitutiva Global ao Projeto de Lei Complementar n. ${ }^{\circ}$ 168/1993. Além disso, o projeto teve 29 emendas, modificando por completo o PL, que angariou apoio popular.

${ }^{2}$ Junto aos crimes contra a economia popular, a fé pública, a administração pública, o patrimônio público, o mercado financeiro, pelo tráfico de entorpecentes e os crimes eleitorais, já presentes na redação original, a "Ficha Limpa" acrescentou à alínea "e" os crimes contra o patrimônio privado, o mercado de capitais e os previstos na lei que regula a falência, contra o meio ambiente e a saúde pública, de abuso de autoridade, de lavagem ou ocultação de bens, direitos e valores, de racismo, tortura, terrorismo e hediondos, de redução à condição análoga à de escravo; contra a vida e a dignidade sexual e os praticados por organização criminosa, quadrilha ou bando.
}

3 “Art. $5^{\circ}$. (...) LVII - ninguém será considerado culpado até o trânsito em julgado de sentença penal condenatória".

4 "STF decide pela constitucionalidade da Lei da Ficha Limpa". Disponível em: <http:// www.stf.jus.br/portal/cms/verNoticiaDetalhe.asp?idConteudo=200495>. Acesso em: 15 ago. 2019.

${ }^{5}$ Art. 16. A lei que alterar o processo eleitoral entrará em vigor na data de sua publicação, não se aplicando à eleição que ocorra até um ano da data de sua vigência. 
Mesmo após sua promulgação e sua aplicação às eleições de 2010, ela não deixou de ser objeto de intensa controvérsia e de diversos estudos ${ }^{6}$. Para muitos, a Lei cumpre o objetivo de moralização da política e representa a resposta ao descontentamento social em relação à corrupção e à improbidade administrativa no exercício dos mandatos em vistas à moralidade. Para outros, a Lei é inconstitucional, tendo em vista que o recrudescimento desproporcional das inelegibilidades e o caráter prospectivo da Lei reduzem os candidatos e as opções dadas à população para eleger seus representantes transferem o poder de escolha ao Judiciário, excluem da disputa eleitoral cidadãos julgados em caráter provisório ou mesmo em razão de decisões proferidas por órgãos administrativos, conselhos de classe e não jurisdicionais e, ainda, diminuem a responsabilidade do povo na escolha de seus representantes (MASCARENHAS, 2012).

Indo além da discussão sobre a constitucionalidade da LC 135/2010, o objetivo deste trabalho é de analisar, com fundamento na teoria da escolha racional aplicada à Ciência Política, o processo de sua aprovação no Congresso Nacional no cenário de forte apelo popular e midiático, para compreender o comportamento e os interesses dos atores políticos envolvidos. A análise proposta, conforme indicado, será realizada a partir do institucionalismo da escolha racional, segundo o qual os atores inseridosem jogos políticos se comportam em vista da satisfação de seus interesses pessoais, e não em busca de um suposto bem comum.

A pergunta que fundamenta este estudo é: a partir de uma análise fundada na teoria da escolha racional, quais foram os fundamentos que levaram à aprovação da Lei da Ficha Limpa? Para esta pergunta, duas são as hipóteses centrais: a primeira delas aponta que os congressistas, ao aprovarem a LFL, buscavam efetivamente a moralização no cenário político, mesmo que a lei pudesse acarretar-lhes prejuízos posteriores; a segunda delas indica que a aprovação correspondeu aos anseios populares e ao objetivo específico de reeleição.

Para responder à pergunta anteriormente indicada, metodologicamente o trabalho buscou realizar uma ampla revisão bibliográfica em torno tanto da LC n. 135/2010, crítica ou favorável ao marco legislativo (além das considerações dos próprios autores da proposta trazida ao Congresso

\footnotetext{
${ }^{6}$ A exemplo dos debates que ainda versam sobre o tema, Ana Cláudia Santano publicou estudo sobre os efeitos da Lei da Ficha Limpa nos cinco anos posteriores à sua aprovação. Segundo a autora, alguns dos principais efeitos negativos da LFL são o forte ativismo judicial que ela propiciou e a instabilidade dos detentores de mandatos eletivos (SANTANO, 2015).
} 
Nacional), quanto da teoria analítica do comportamento dos congressistas, proveniente da Ciência Política. Ainda, a fim de confrontar essas considerações teóricas com o contexto político e social à época de sua aprovação, o artigo buscou diversas matérias da imprensa nacional que retratavam não somente os discursos dos parlamentares responsáveis pela LFL, mas também as pressões sociais exercidas naquele momento.

\section{Lei da Ficha Limpa: a ampliação das hipóteses de inelegibilidade diante do confronto entre soberania popular e moralidade política}

A Constituição Federal anuncia, em seu artigo 1ํㅗ parágrafo único, que "todo o poder emana do povo, que o exerce por meio de representantes eleitos ou diretamente [...].". Além de outras formas de exercício do poder, estabelece o texto constitucional que este será exercido pelo povo de forma mediata - isto é, por meio de representantes eleitos no processo eleitoral.

As eleições são a base da democracia representativa. Segundo Dahl, a realização de governos democráticos em unidades políticas do tamanho de países tornou necessárias as eleições. Embora represente uma solução imperfeita, a disputa eleitoral permite que os cidadãos escolham seus funcionários mais importantes e mantenham-nos de algum modo responsáveis frente à possibilidade da não reeleição nas eleições seguintes (DAHL, 2001, p. 107). Diante disso, a democracia requer eleições livres, justas e frequentes (DAHL, 2001, p. 109).

Para Schumpeter, um elemento indispensável ao sucesso da democracia representativa é a qualidade dos candidatos aos cargos políticos. Torna-se necessária, assim, a criação de instrumentos que garantam a participação dos candidatos mais qualificados na disputa política (SCHUMPETER, 1984, p. 361-362).

Verifica-se, com isso, que o predomínio do modelo representativo de democracia traz à tona a questão da aptidão do cidadão de participar de um certame eleitoral e de ser eleito, de acordo com as condições definidas pela Constituição ${ }^{7}$. Na Carta estão previstas, no artigo 14, parágrafo $3^{\circ}$, as condições de elegibilidade e, nos parágrafos $4^{\circ}$ a $8^{\circ}$, as hipóteses que conduzem à situação de inelegível. O parágrafo 9º por sua vez, define que "lei

\footnotetext{
${ }^{7}$ De acordo com Celso Bastos, "a elegibilidade consiste no exercício do direito político passivo, é dizer, na capacidade de receber os votos dos eleitores. É, portanto, elegível aquele que reunir as condições exigidas para concorrer eleitoralmente". (BASTOS, 1993, p. 15)
} 
complementar estabelecerá outros casos de inelegibilidade e os prazos de sua cessação [...]", com o objetivo de proteger a probidade e a moralidade para exercício do cargo.

A elegibilidade é a condição fundamental da democracia representativa e, como decorrência, as inelegibilidades somente podem ser definidas por meio de norma constitucional ou lei complementar, pois "representam uma limitação clara à soberania popular." (AGRA, 2012, p. 152). Devem, ainda, ser interpretadas restritivamente, de modo a não impedir o funcionamento do regime democrático.

Na democracia, a inelegibilidade possui três fundamentos éticos: a manutenção e o funcionamento do regime democrático, para garantir a moralidade e a neutralidade em face do poder econômico e político, a defesa do princípio da isonomia, para garantir que todos os cidadãos tenham igual chance na disputa política, e a salvaguarda do princípio republicano, para garantir que todos os cidadãos possam ocupar cargos públicos e evitar que determinados grupos políticos ou familiares perpetuem-se no poder (GODOY; BORGES, 2018). Assim, a garantia da elegibilidade pode sofrer limitações, contanto que a restrição apresente um fundamento ético subjacente e busque proteger a legitimidade do processo eleitoral contra possíveis abusos de poder.

Por intermédio da Lei Complementar n. 135, houve a alteração da LC 64/1990 e o recrudescimento das hipóteses de inelegibilidade. Dentre as principais mudanças promovidas pela LFL, destacam-se a previsão de crimes cuja condenação atrai a impossibilidade de candidatura; o aumento dos prazos para oito anos; a desnecessidade de trânsito em julgado da decisão condenatória para a incidência da restrição da participação nas eleições e o acréscimo de hipóteses de limitação ao direito do cidadão de concorrer na disputa eleitoral.

São dois os aspectos mais polêmicos da Lei: a retroatividade a fatos pretéritos à sua entrada em vigor, apesar da regra da anualidade do artigo 16 da Constituição e a antecipação da inelegibilidade ao trânsito em julgado da sentença condenatória, a despeito da garantia de presunção de inocência, prevista no art. 5º, LVII, da Constituição. Pouco tempo após sua entrada em vigência, o Supremo Tribunal Federal julgou as Ações Declaratórias de Constitucionalidade n. ${ }^{\circ} 29$ e 30 e a Ação Direta de Inconstitucionalidade $\mathrm{n}^{\mathrm{o}} 4.578$, decidindo, por apertada maioria, a constitucionalidade da Lei da Ficha Limpa. 
Com efeito, a Lei Complementar 135/2010 tem como objetivo declarado a garantia da moralidade no âmbito político e no exercício dos mandatos representativos. A partir do suposto propósito de moralização, a LC 135/2010 limita a possibilidade de os cidadãos participarem do pleito político, restringindo, nitidamente, os direitos políticos. Pela Lei da Ficha Limpa, segundo parte da doutrina, retirou-se do povo a possibilidade de escolher livremente seus representantes e, por consequência, limitou-se a soberania popular, partindo do pressuposto de que os eleitores devem ser tutelados ${ }^{8}$.

Compreendidas as alterações empreendidas pela LC n. 153/2010 e os propósitos nos quais ela foi supostamente fundamentada, pretende-se, nos tópicos subsequentes, analisar o comportamento dos atores responsáveis pela aprovação e pela aplicação da Lei da Ficha Limpa para além do discurso de moralização da política, na tentativa de entender as razões que levaram o Congresso Nacional a aprová-la naquele contexto histórico. Para isso, utilizar-se-á como suporte teórico a teoria da escolha racional, segundo a qual os atores envolvidos em decisões políticas agem de acordo com seus próprios interesses e sempre na tentativa de maximizar seus benefícios.

\section{As contribuições da teoria da escolha racional na ciência política}

De acordo com Ward, a teoria da escolha racional surgiu nos Estados Unidos, entre as décadas de 1950 e 1960, com o objetivo de analisar o comportamento dos indivíduos com base em métodos empíricos e a partir do pressuposto de que as pessoas atuam para atender seus próprios interesses (WARD, 2002, p. 66). Essa abordagem teórica é utilizada em diversas áreas das ciências sociais, como decorrência da aplicação da teoria econômica segundo a qual prevalece, no modelo de conduta humana, a racionalidade consciente. Definida tradicionalmente como teoria positiva9 ${ }^{9}$, esta tem

\footnotetext{
${ }^{8}$ Críticos à Lei da Ficha Limpa, Eneida Desiree Salgado e Eduardo Borges Araújo afirmam que esta "é símbolo de um perigoso encontro entre discurso jurídico e moralidade — uma moralidade perniciosa que desafia os fundamentos do Estado Democrático de Direito e que contraria os princípios da legalidade, da irretroatividade de restrições aos direitos fundamentais, da proteção e da confiança”. (SALGADO; ARAÚJO, 2013, p. 123)

${ }^{9} \mathrm{Em}$ tese, as teorias da escolha racional não têm por objetivo definir como os atores devem atuar, mas como eles de fato atuam. De acordo com Farejohn e Pasquino, no entanto, "as próprias teorias da escolha racional são mais bem classificadas como teorias normativas do que como teorias positivas", isso porque, segundo os autores, não é possível acreditar
} 
por objetivo prever fenômenos sociais por meio de modelos explicativos da ação individual ${ }^{10}$.

Também sob influência do pensamento econômico, na Ciência Política a teoria da escolha racional foi inserida por meio do estudo de autores como Anthony Downs, Mancur Orsen e Gordon Tullock. Muito embora esses autores divirjam em diversos aspectos, todos defendem que "os agentes sociais estariam interessados na maximização da riqueza, de votos, ou de outras dimensões mais ou menos mensuráveis em termos de quantidades e sujeitas a constrangimentos de recursos materiais" (FEREJOHN; PASQUINO, 2001, p. 05). Assim, de acordo com essa perspectiva teórica, os envolvidos em jogos políticos têm por objetivo maximizar sua satisfação com a menor utilização de recursos.

Parte-se do pressuposto de que os seres humanos são dotados de racionalidade e, por consequência, agem de modo estratégico a fim de maximizar suas preferências. Nesse sentido, Downs afirma que ação racional é aquela definida para alcançar as finalidades econômicas ou políticas conscientemente escolhidas pelo ator. A partir disso, o objetivo do autor na obra Uma Teoria Econômica da Democracia é de construir um modelo que esclareça como um governo racional se comporta em um Estado democrático (DOWNS, 1999, p. 35).

Para Downs, de acordo com o pressuposto da conduta racional dos indivíduos, aqueles que estão no poder buscam maximizar o apoio político. Isso significa que os ocupantes de cargos políticos adotarão as alternativas que presumivelmente a maioria dos eleitores prefere, com o objetivo de elevar ao máximo o número de votos nas próximas eleições. Conclui-se, com isso, que os partidos políticos formulam políticas com o intuito de ganhar eleições, ao invés de ganharem eleições para formularem políticas. Por outro lado, os cidadãos votam nos políticos que acreditam poder lhes

que os seres humanos atuam exatamente do modo como essas teorias prescrevem. Mas, "ainda assim, mesmo não agindo racionalmente, as pessoas tendem a reconhecer a força normativa da racionalidade, e isso influencia as suas ações — que se aproximam ao menos um pouco daquilo que criaturas de racionalidade ideal fariam nas mesmas circunstâncias". (FEREJOHN; PASQUINO, 2001, p. 05-06)

${ }^{10}$ Trata-se do individualismo metodológico, segundo o qual os fenômenos sociais podem ser explicados através das ações dos indivíduos que operam sob determinadas coerções. (TSEBELIS, 1999, p. 35) 
proporcionar mais benefícios que quaisquer outros - agem, portanto, racionalmente $^{11}$.

Para Tsebelis, também adepto da teoria da escolha racional, a racionalidade "nada mais é que uma correspondência ótima entre fins e meios" (TSEBELIS, 1998, p. 33). Na obra Jogos Ocultos: Escolha Racional no Campo da Política Comparada, Tsebelis busca, a partir da teoria da escolha racional e da teoria dos jogos, demonstrar que o comportamento dos atores dentro do processo político é previsível. Segundo o autor, a teoria da escolha racional fundamenta-se no pressuposto de que cada ator ou jogador, tendo as informações adequadas, fará a escolha que assegure a maximização do seu payoff - isto é, da retribuição recebida pela escolha realizada (TSEBELIS, 1998, p. 25).

O ponto central da obra é de que escolhas aparentemente subótimas dos atores da arena política - que estejam munidos da informação adequada - representam, na verdade, uma assimetria entre aquilo que o ator realiza e o que o observador pode ver. Isso ocorre porque enquanto o ator está atuando em múltiplas arenas, o observador enxerga apenas um jogo, sem considerar que fatores contextuais ou institucionais têm uma importância predominante para definir a escolha do jogador (TSEBELIS, 1998, p. 25-26). O foco do autor é de ressaltar a racionalidade das condutas dos agentes na seara política, que visam sempre maximizar seu payoff.

Diversas são as críticas enfrentadas pela teoria da escolha racional. Dentre elas, questiona-se se é realista o enfoque da teoria da escolha racional - isto é, se de fato os indivíduos agem pautados pela racionalidade. Ainda, aponta-se como limitação a tendência dos teóricos da escolha racional de "dar sentido às práticas sociais atribuindo a elas racionalidade ex post facto". Indica-se, também, que vários teóricos dessa vertente tendem a desconsiderar ou a igualar a diversidade cultural ${ }^{12}$. Não se pretende, neste estudo, analisar em profundidade as limitações da teoria da escolha racional, mas compreender suas contribuições para o problema proposto.

\footnotetext{
${ }^{11}$ Sobre isso, Ward afirma que: "The individual vote to the party which, if it got into office, is expected to yield them the highest utility. Parties are assumed to be motivated solely by the desire for office, competing for votes by changing their policy platforms". (WARD, 2002, p. 66)

${ }^{12}$ Tais críticas são apontadas detalhadamente por Patrick Baert, no artigo "Algumas limitações das explicações da escolha racional na Ciência Política e na Sociologia”. (BAERT, 1997)
} 
Um importante aporte da teoria da escolha racional é de se contrapor à visão clássica da disciplina de Teoria do Estado e Ciência Política dos cursos de Direito, segundo a qual a atividade política tem por objetivo a realização do bem comum ${ }^{13}$. Com efeito, os teóricos da escolha racional têm como semelhança o objetivo de demonstrar como os sujeitos de fato atuam em determinado campo, e não como deveriam atuar. De acordo com a abordagem adotada, os indivíduos não agem na arena política em vistas ao bem-estar coletivo, mas em busca da maximização do seu payoff. Esta análise realista permite desmistificar o discurso comumente empregado no campo político ao revelar a conduta egoísta dos atores neste campo.

\section{Para além do discurso moralizador: atores e seus interesses na aprovação da lei da ficha limpa}

O principal fundamento utilizado quando da aprovação da Lei da Ficha Limpa foi de um suposto resgate da probidade administrativa no exercício dos mandatos políticos. Nesse sentido, o objetivo de moralização da política é anunciado já no preâmbulo da Lei (em repetição do art. 14, § 9, da Constituição), que indica a inclusão de "hipóteses de inelegibilidade que visam a proteger a probidade administrativa e a moralidade no exercício do mandato".

De acordo com Márlon Reis, autor do projeto que angariou apoio popular e culminou na $\mathrm{LC}^{\circ}{ }^{\circ} 135 / 2010$, o fundamento da condição de inelegível é o "princípio da proteção", que estabelece um "mínimo esperado" dos postulantes a cargos eletivos e autoriza a lei a delinear negativamente o perfil de candidatos, "buscando evitar que o futuro posto venha a ser alcançado por quem se enquadre em uma das hipóteses de exclusão" (REIS, 2010, p. 31).

\footnotetext{
${ }^{13}$ De acordo com a abordagem tradicional da Teoria do Estado e da Ciência Política, a atuação do Estado tem como finalidade a busca pelo bem comum. Nesta perspectiva, afirma Dallari que a razão de ser do Estado é a garantia do bem comum, conceituado de modo "extremamente feliz", nas palavras do autor, pelo Papa João XXII, como o "conjunto de todas as condições de vida social que consintam e favoreçam o desenvolvimento integral da personalidade humana". Ainda nesta abordagem, o Estado é a ordem jurídica soberana que tem por finalidade o bem comum de um povo, localizado em certo território (DALLARI, 1989, p. 16-32). A utilidade da noção de bem comum para a Filosofia Política é questionável por ser imprecisa; por pressupor a homogeneidade dos interesses dos indivíduos que compõem o povo; e por fundamentar uma concepção normativa de Estado, enfocada no dever-ser do ente estatal e afastada da realidade social - fundamentando, assim, uma visão encantada de Estado e de democracia.
} 
Em outras palavras, o discurso que deu fundamento à Lei da Ficha Limpa e que levou à sua aprovação é embasado na noção abstrata de bem comum e de moralidade da política. Para além do discurso utilizado, questiona-se, no entanto, as razões que levaram os congressistas a aprovarem uma lei que poderia eventualmente restringir sua futura participação em eleições. Nesse sentido, a compreensão das razões que culminaram na aprovação da Lei Complementar 135/2010 requer análise de seu histórico e do contexto de sua aprovação.

É possível afirmar que a gênese da Lei da Ficha Limpa está relacionada à criação da Lei n. 9840/1998 - que alterou a legislação eleitoral para prever a cassação do registro da candidatura ou do diploma daqueles que cometessem compra de votos e uso eleitoral da máquina pública e com o surgimento do Movimento de Combate à Corrupção Eleitoral (MCCE), em 2002 ${ }^{14}$. Decorrente de iniciativa popular, a Lei n. 9840/1998 contou com intensa mobilização social, tendo ao final angariado mais de um milhão de assinaturas. Encaminhada à Câmara dos Deputados, a lei foi aprovada rapidamente.

Muito embora considerada por Márlon como um grande avanço democrático, entendia o autor que a Lei n. 9840/98 apresentava certa limitação, pois a punição pela compra de votos não impedia que o candidato recaísse na mesma conduta em uma próxima campanha ou o fizesse mediante "laranjas" (REIS, 2013, p. 90-91). Por conta disso, nas palavras de Reis, "resolvemos dar um passo atrás. Em vez de darmos atenção à campanha, decidimos focar na definição do candidato. E foi aí que criamos a Lei da Ficha Limpa” (REIS, 2013, p. 91).

A proposta da Ficha Limpa é consequência direta dos escândalos de corrupção que passaram a ser intensamente divulgados entre as décadas

${ }^{14}$ Conforme informações obtidas no sítio eletrônico do MCCE, o movimento "foi instituído durante o período eleitoral de 2002. Mas pode-se dizer que a campanha da fraternidade de 1996, que teve por tema "Fraternidade e Política", contribuiu para aflorar a criação do MCCE, porque posterior à campanha, a Comissão Brasileira Justiça e Paz (CBJP), órgão vinculado da Conferência Nacional dos Bispos do Brasil (CNBB), lançou o Projeto “Combatendo a corrupção eleitoral” em fevereiro de 1997. Assim, era plantada, em 1998, a semente da iniciativa popular contra a corrupção eleitoral, originando a Lei 9840. Fundado durante o período eleitoral de 2002, o MCCE ampliou sua atuação e hoje funciona de forma permanente com ações em todo o país. Em 2006, é criada a Secretaria Executiva do Comitê Nacional do MCCE. Em 27 de abril de 2007, é oficializada legalmente a Secretaria Executiva do Comitê Nacional do Movimento de Combate à Corrupção Eleitoral (SE-MCCE), organização não governamental (ONG) e sem fins lucrativos.”. 
de 1990 e 2000. Conforme explicado por Fátima Anastasia e Luciana Santana, de Collor a Lula, a lista de escândalos é extensa: os Anões do Orçamento, a CPI do Banestado, a CPI dos Bingos, a Emenda da Reeleição, a CPI dos Correios, o Mensalão, o Mensalinho, o Escândalo das Sanguessugas, dentre outros (ANASTASIA; SANTANA, 2008, p. 363). Neste contexto de descrença no potencial das instituições e das leis até então existentes para conter a corrupção, a Campanha Ficha Limpa teve início com o objetivo de pressionar o Congresso para a criação de uma lei que viesse a recrudescer as hipóteses de inelegibilidade.

A aprovação da Lei da Ficha Limpa foi precedida de mobilização popular e de entidades sociais. Sobre isso, Fux e Frasão afirmam que a lei representa o fortalecimento das instituições democráticas brasileiras, "porquanto resultou de intensa mobilização da sociedade civil organizada, que formalizou projeto junto à Câmara dos Deputados, subscrito por mais de um milhão e trezentos mil cidadãos, importante mecanismo de democracia direta e participativa" (FUX; FRASÃO, 2016, p. 121-122). Dentre as instituições que se mobilizaram para a obtenção das assinaturas e posterior aprovação da Lei, cabe citar a $\mathrm{CNBB}^{15}$ e a Ordem dos Advogados do Brasil - OAB. Para estas entidades, a definição de critérios mais rígidos para acesso a cargos representativos visava à elevação do nível das disputas eleitorais e à proteção aos eleitores.

A mobilização social para aprovação da Lei da Ficha Limpa demonstrou a insatisfação generalizada com o sistema político e com a corrupção, a qual fundamentou o pleito de aprofundamento das instituições e de recrudescimento das normas, com o intento de afastar da vida pública aqueles que estivessem envolvidos em condutas ilícitas, imorais e antiéticas (DE ABREU E SILVA, 2015, p. 31). Sobre isso, em seu voto no julgamento da convencionalidade da LC 152/2010, Fux afirmou que "não é novidade que há muito a sociedade civil organizada reclama por ética e por moralidade no exercício desse munus público, que é tornar-se um representante eleito, um agente político".

Muito embora de constitucionalidade questionável pelas razões anteriormente apresentadas e apesar de possibilitar uma futura restrição

\footnotetext{
${ }^{15}$ CNBB, "A aprovação do ficha limpa é questão de dignidade para o Legislativo", afirma dom Angélico Sândalo, 48ª Assembleia Geral da CNBB. 2010. Disponível em: < http:// www.cnbb.org.br/a-aprovacao-do-ficha-limpa-e-questao-de-dignidade-para-o-legislativo-afirmou-dom-angelico-sandalo/>. Acesso em: 12 ago. 2019.
} 
à capacidade eleitoral passiva dos congressistas, a Lei da Ficha Limpa cujo projeto de iniciativa popular foi apresentado à Câmara dos Deputados em 29 de setembro de 2009, acompanhado da assinatura de mais um milhão e trezentas mil pessoas - foi promulgada em junho de 2010. O PLP $518 / 2009$, a partir do qual foi originada a LC 135/2010, apesar de amplamente alterado pelo Congresso Nacional, tramitou rapidamente na Câmara dos Deputados.

Em apenas 248 dias de tramitação, o projeto teve seu conteúdo transformado em lei, por acatamento de emenda substitutiva global ao PLP no 168/1993 (CAMPOS, 2018). Considerando o estudo de José Álvaro Moisés, segundo o qual um projeto de lei subscrito por parlamentar leva em média 964,8 dias para ser aprovado (MOISÉS, 2011, p. 18), conclui-se que o trâmite da Lei da Ficha Limpa foi mais célere que o padrão.

Diante disso, verifica-se que a forte mobilização da sociedade civil subjacente à iniciativa popular exerceu influência para a rápida aprovação da Lei da Ficha Limpa pelo Congresso. Não é possível, no entanto, compreender que essa aderência dos congressistas ao apelo popular decorreu de uma suposta preocupação com o bem comum e com a moralidade na esfera política. Em verdade, partindo de uma análise institucionalista da escolha racional, os parlamentares se envolvem em atividades que assegurem a renovação do seu mandato. Nesse sentido, diante de tamanha mobilização popular em relação ao projeto que culminou na LFL, aprová-lo representou um fator importante para a reeleição.

De acordo com o institucionalismo racional, o comportamento dos atores na seara política é previsível, pois a tendência é agirem de modo a garantir a maximização dos votos em vistas à reeleição. Nesse sentido, Downs afirma que "como cada cidadão adulto tem direito a um voto, suas preferências de bem-estar são pesadas aos olhos do governo, que está interessado apenas em seu voto, não em seu bem-estar". Ainda de acordo com o autor, "o governo sempre escolhe a alternativa que a maioria dos eleitores prefere" (DOWNS, 1999, p. 40).

Sobre essa questão, é necessário considerar a teoria da conexão eleitoral, de David Mayhew, para quem a reeleição exerce forte influência no comportamento parlamentar. Afirma o autor, ao analisar o Congresso dos Estados Unidos, que este é formado especialmente por políticos profissionais e que isso se deve ao fato de que a função garante boa remuneração e alto prestígio (MAYHEW, 1974, p. 14-15). De modo geral, para obter sucesso na reeleição, três atividades básicas são necessárias aos congressistas: 
a autopromoção ou publicidade, a reivindicação de crédito e a tomada de posição. Muito embora haja diferenças entre os sistemas eleitorais brasileiro e estadunidense - a exemplo da inexistência do voto distrital no Brasil -, o estudo de Mayhew oferece importante subsídio ao tema ora estudado, especialmente quanto à tomada de posição ${ }^{16}$.

A tomada de posição é definida como a manifestação pública do parlamentar sobre um tema de grande relevância ou sobre uma política pública. Segundo Mayhew, "as formas pelas quais as posições, aparições podem ser registradas são numerosas e, frequentemente, criativas. (...) Há discursos para pequenos grupos, aparições na TV, cartas, jornais, press releases, artigos da Playboy, até mesmo entrevistas com cientistas políticos". O importante, nesse sentido, é que o parlamentar assuma a posição que a maioria de seus eleitores tende a preferir sobre uma determinada questão.

No caso da Lei da Ficha Limpa, tamanha foi a mobilização social subjacente para a aprovação da lei que o PLP n ${ }^{0}$ 168/1993 - naquele momento em trâmite no Congresso há dezesseis anos - ganhou velocidade após o apensamento do PLP n⿳0518/2009 e teve célere aprovação. Conclui-se que, durante o período de mais de uma década e meia em que o projeto esteve parado, este não representava uma prioridade do governo ou dos partidos. Mas, com o advento do projeto de lei de iniciativa popular, a matéria se tornou prioritária na agenda do Congresso Nacional (CAMPOS, 2013).

Como visto, a atenção sobre o projeto à época era imensa. Prestes a ser votado o regime de urgência em sua tramitação, em maio de 2010, o apoio virtual à lei chegava a dois milhões de assinaturas ${ }^{17}$. Antes de sua

${ }^{16}$ Quanto à publicidade, este é o modo de manter o elo entre eleitor e seu representante. Dentre as rotinas publicitárias padrão, Mayhew cita visitas frequentes ao distrito eleitoral, discursos não políticos para pequenos públicos, envio de folhetos sobre cuidados na infância e cartas de condolência e felicitação. A busca de crédito, por outro lado, significa agir de forma a gerar uma crença em um ator político relevante de que alguém é pessoalmente responsável por uma ação do governo - ou de alguma de suas unidades - que o ator considere desejável.

${ }^{17}$ Sobre isso, noticiou o portal Congresso em Foco que "Cresce a pressão sobre os deputados para aprovar a proposta que restringe a candidatura de políticos com problemas na Justiça, o chamado projeto Ficha Limpa. Passa de 2 milhões o número de assinaturas de apoio à proposição coletadas na internet por meio do site da organização não governamental Aavaz (www.avaaz.org), parceira do Movimento de Combate à Corrupção Eleitoral (MCCE), responsável pela apresentação do projeto de lei de iniciativa popular.”. Disponível em <https://congressoemfoco.uol.com.br/especial/noticias/ficha-limpa-mais-de-2-milhoes-de-assinaturas-na-internet/> Acesso em: 10 ago. 2019. 
aprovação, em junho, já começavam os levantamentos dos políticos que seriam atingidos pelos impedimentos do novo diploma ${ }^{18}$. Após a sua aprovação, entidades chegaram a lançar um serviço para cadastramento de candidatos que quisessem ter atestada publicamente sua condição de "Ficha Limpa" para o eleitor ${ }^{19}$.

Em resumo, a mobilização de diversas entidades e a cobertura dos meios de comunicação sobre o projeto da "Ficha Limpa" em pleno ano eleitoral contribuíram diretamente para que as expectativas da sociedade crescessem em torno de sua aprovação. Ao passo que o projeto caminhava no Congresso, fortalecia-se a narrativa de ambivalência dos "maus" contra os "bons" no embate que levou ao trâmite em tempo recorde e à vigência da Lei no mesmo ano de sua sanção ${ }^{20}$. Opor-se ao PLP impunha um ônus aos congressistas que, no período crítico de sua discussão, não poderia ser racionalmente tolerado. Só se opunha quem, em tese, temia os efeitos da nova lei ${ }^{21}$.

Com efeito, a suposta insatisfação popular, a mobilização de entidades da sociedade civil, bem como o forte apelo midiático funcionaram como propulsores no caso da Lei da Ficha Limpa, tanto para tornar o projeto prioritário na agenda parlamentar como para que este angariasse apoio

\footnotetext{
${ }^{18}$ Em 24 de junho de 2010, o portal Congresso em Foco noticiou matéria intitulada "Veja lista de 42 políticos na mira do ficha limpa". Disponível em <https://congressoemfoco. uol.com.br/eleicoes/veja-lista-de-42-politicos-na-mira-do-ficha-limpa/> Acesso em 05 ago. 2019.

${ }^{19}$ Sobre isso, o portal G1 publicou: "Site criado para candidatos com 'ficha limpa' recebe 36 inscrições". Disponível em <http://g1.globo.com/especiais/eleicoes-2010/noticia/2010/08/site-criado-para-candidatos-com-ficha-limpa-recebe-35-inscricoes.html >.

Acesso em 05 ago. 2019.

${ }^{20} \mathrm{O}$ que levantou mais questionamentos acerca de sua compatibilidade com o art. 16 da Constituição.

${ }^{21}$ Nesse sentido, o sítio eletrônico do Terra noticiou que "Um dos maiores opositores ao projeto Ficha Limpa no Congresso, o líder do governo no Senado, Romero Jucá (PMDB-RR) responde na Justiça a acusações de que teria cometido ilícitos tributários. Enquanto Jucá articula o adiamento da votação do Ficha Limpa, o que impossibilitaria que o projeto valesse nas eleições de outubro, o Supremo Tribunal Federal (STF) deve analisar na semana que vem o pedido de prorrogação do prazo para uma investigação contra o senador.”. Disponível em <https://www.terra.com.br/noticias/brasil/politica/opositor-do-ficha-limpa-juca-responde-a-processos-no-stf,c78b63fc8940b310VgnCLD200000bbcceb0aRCRD. html>. Acesso em 08 ago. 2019.
} 
quase absoluto dos congressistas ${ }^{22}$. Essa mobilização ${ }^{23}$ foi além. Ainda que não seja o escopo desse texto, não é equivocado dizer que a escolha racional também foi o que levou tribunais eleitorais e os próprios ministros do STF a avalizar a aplicação plena e quase que imediata da nova lei já no pleito de 2010 .

\section{Considerações finais}

Uma das principais contribuições da teoria da escolha racional aplicada à Ciência Política é de desvelar o comportamento 'egoísta' daqueles que atuam no campo político representativo. De acordo com esta perspectiva teórica, aqueles que estão no poder buscam maximizar o apoio político e os votos, de modo que agem não buscando o melhor para a sociedade, mas aquilo que lhes garante os maiores benefícios. Nesse objetivo, a pressão de grupos sociais organizados e uma ampla cobertura midiática exercem influência direta no alinhamento entre a atuação do representante e as expectativas de ganho político futuro junto a seu eleitorado.

Ao analisar a Lei Complementar 135/2010 pelas lentes do institucionalismo racional, conclui-se que, muito embora fundamentada em um suposto discurso de moralidade e de bem comum, a aprovação da Lei da Ficha Limpa decorreu, em verdade, do forte apelo popular e midiático ocorrido em um período marcado pela divulgação de diversos eventos de corrupção. Considerando que o propósito de reeleição modula a conduta parlamentar e que, em vistas a este objetivo, os congressistas devem atender aos interesses de seu eleitorado, a LFL foi rapidamente aprovada em virtude da iniciativa popular.

O início do trâmite durante um ano de eleições gerais e a eficiente cooptação do discurso moral pela imprensa e os grupos interessados em sua aprovação contribuíram diretamente para que a LFL tivesse apressada

\footnotetext{
${ }^{22}$ Dos 513 deputados, 390 participaram da sessão que aprovou o texto-base do projeto Ficha Limpa e, destes, apenas um votou contra. O deputado Marcelo Melo (PMDB-GO), único a votar conta, alegou que, em virtude do cansaço, equivocou-se ao digitar seu voto. Os outros 123 parlamentares faltaram à sessão. ("Quem aprovou o ficha limpa: veja como os deputados votaram”. Disponível em <https://congressoemfoco.uol.com.br/especial/ noticias/quem-aprovou-o-ficha-limpa-veja-como-os-deputados-votaram/>. Acesso em 05 ago. 2019.

23 “Manifestação pró Ficha Limpa acontece em frente ao Tribunal Regional Eleitoral, em Brasília". Disponível em <http://www.cnbb.org.br/manifestacao-pro-ficha-limpa-acontece-em-frente-ao-tribunal-regional-eleitoral-em-brasilia/>. Acesso em 01 ago. 2019.
} 
votação nas duas Casas e sanção pelo então presidente Lula, bem como validade para aquele pleito. As declarações públicas dos parlamentares envolvidos à época revelaram claramente os payoffs advindos do apoio a uma aprovação rápida da lei, mesmo que a matéria de fundo a ser votada implicasse em prejuízos futuros a eles e ou a suas bases de apoio.

É questionável a constitucionalidade da Lei, bem como o atingimento, nesses nove anos, dos seus objetivos declarados. É inquestionável, no entanto, que a mobilização de diversas entidades e a intensa cobertura dos veículos de comunicação sobre o projeto de lei em pleno ano eleitoral contribuíram diretamente com sua célere aprovação. É nítido, com isso, que, especificamente no caso da Ficha Limpa, as decisões políticas e o comportamento dos players decorreram em considerável medida de aspectos estruturais envolvidos naquele momento específico.

\section{Referências}

AGRA, Walber de Moura. Temas polêmicos do direito eleitoral. Belo Horizonte: Fórum, 2012.

ANASTASIA, Fátima; SANTANA, Luciana. Sistema Político. AVRITZER et al (orgs.). Corrupção: ensaios e críticas. Belo Horizonte: Editora UFMG, 2008, p. 363-371.

BASTOS, Celso. Limites das inelegibilidades dos prefeitos municipais. Cadernos de Direito Constitucional e Eleitoral. n. 20. São Paulo: Imprensa Oficial do Estado, nov.-jan. 1992-1993.

BRASIL. Constituição (1988). Constituição da República Federativa do Brasil. Brasília, 1988. Disponível em <http://www.planalto.gov.br/ccivil_03/constituicao/constituicao.htm>. Acesso em: 22 ago. 2019.

. Lei Complementar n. 135 de 04 de jun. de 2010. Disponível em <http://www.planalto.gov.br/ccivil_03/leis/lcp/Lcp135.htm>. Acesso em: 15 ago. 2019.

BAERT, Patrick. Algumas limitações das explicações da escolha racional na Ciência Política e na Sociologia. Revista Brasileira de Ciências Sociais, São Paulo, v. 12, n. 35, out. 1997. Disponível em: http://www.scielo.br/scielo. php?script=sci_arttext\&pid=S0102-69091997000300005. Acesso em: 20 ago. 2019. 
CAMPOS, Alex Machado. Ficha Limpa e a resposta congressual: comportamento legislativo e processo decisório. Revista Eletrônica do Programa de Pós-Graduação da Câmara dos Deputados, Brasília, DF, 12, dez. 2013. Disponível em: <http://e-legis.camara.leg.br/cefor/index.php/e-legis/article/view/154>. Acesso em: 10 set. 2019.

DAHL, Robert. Sobre a democracia. trad. de Beatriz Sidou. Brasília: Editora Universidade de Brasília, 2001.

DALLARI, Dalmo de Abreu. Elementos de teoria geral do estado. São Paulo: Saraiva, 1989.

DE ABREU E SILVA, Guilherme. A experiência da lei da ficha limpa nas eleições de 2012: uma análise do perfil dos impugnados e dos reflexos da aplicação da lei. 2015. 88 f. Dissertação (Mestrado em Ciência Política) Setor de Ciências Humanas, Letras e Artes, Universidade Federal do Paraná, 2015.

DOWNS, Anthony. Uma teoria econômica da democracia. São Paulo: Edusp, 1999.

FEREJOHN, John; PASQUINO, Pasquale. A Teoria da Escolha Racional na Ciência Política: Conceitos de racionalidade em teoria política. Revista Brasileira de Direitos Sociais, v. 16, n. 45, p. 05-24, 2001.

FERREIRA, Marcelo Ramos Peregrino. O controle de convencionalidade da lei da ficha limpa: direitos políticos e inelegibilidades - edição atualizada com a Lei no 13.165, de 29 de setembro de 2015. Rio de Janeiro: Lumen Juris, 2016.

FUX, Luiz; FRASÃO, Carlos Eduardo. Novos paradigmas do direito eleitoral. Belo Horizonte: Fórum, 2016.

GODOY, Miguel; BORGES, Eduardo. Diálogos em torno de um conceito indeterminado. In: FUX, Luiz; PEREIRA, Luiz Fernando Casagrande; AGRA, Walber de Moura (coord.); PECCININ, Luiz Eduardo (Org.). Tratado de Direito Eleitoral. V.1 (Direito Constitucional Eleitoral). Belo Horizonte: Fórum, 2018.

MASCARENHAS, Rodrigo Tostes de Alencar. A Lei da "Ficha Limpa": Uma responsabilidade prospectiva? A que preço? In: Revista da Seção Judiciária do Rio de Janeiro. v. 19. n. 34. Ago./2012.

MAYHEW, David. Congress: The Electoral Connection. New Haven: Yale University Press, 1974. 


\section{MOISÉS, José Álvaro. O papel do Congresso Nacional no presiden-} cialismo de coalizão. Rio de Janeiro: Fundação Konrad Adenauer, 2011. Disponível em <http://www2.senado.leg.br/bdsf/bitstream/handle/ $\mathrm{id} / 242412 /$ livropapeldocongresso.pdf ?sequence=1>. Acesso em: 12 ago. 2019.

REIS, Márlon Jacinto. O princípio constitucional da proteção e a definição legal das inelegibilidades. In: REIS, Márlon Jacinto; OLIVEIRA, Marcelo Roseno de; CASTRO, Edson Resende de (Orgs.). Ficha Limpa: Lei Complementar n. ${ }^{\circ}$ 135, de 4.6.2010 interpretada por juristas e responsáveis pela iniciativa popular. São Paulo: Edipro, 2010.

, Márlon Jacinto. O gigante acordado: manifestações, ficha limpa e reforma política. Rio de Janeiro: LeYa, 2013.

SALGADO, Eneida Desiree. A elegibilidade como direito político fundamental, as inelegibilidades retroativas da lei complementar 135/10 e a (in)decisão do Supremo Tribunal Federal. In: MONTEIRO, Roberto Corrêa de Araújo; ROSA, André Vicente Pires (coords.). Direito Constitucional - Os Desafios Contemporâneos - Uma Homenagem ao Professor Ivo Dantas. Curitiba, Juruá, p. 193-218, 2012.

, Eneida Desiree; ARAÚJO, Eduardo Borges. Do Legislativo ao Judiciário - A Lei Complementar nº 135/2010 ("Lei da ficha limpa"), a busca pela moralização da vida pública e os direitos fundamentais. Revista de Direito Administrativo e Constitucional - A\&C. Belo Horizonte, ano 13, n.54, out./dez. 2013.

SANTANO, Ana Claudia. 2015. A democracia em tempos contramajoritários: os efeitos da lei da Ficha Limpa após 5 anos de sua aplicação. In XII Seminário Internacional de Demandas Sociais e Políticas Públicas na Sociedade Contemporânea. VIII Mostra de Trabalhos Jurídicos Científicos. Departamento de Direito - Curso de Direito CEPEJUR. Disponível em: <http:// online.unisc.br/acadnet/anais/index.php/sidspp/article/view/13057>.

Acesso em: 10 ago. 2019.

SCHUMPETER, Joseph. Capitalismo, socialismo e democracia. Rio de Janeiro: Zahar Editora, 1984.

TSEBELIS, George. Jogos ocultos: escolha racional no campo da política comparada. São Paulo: Edusp, 1998. 
WARD, Hugh. Rational choice. In: MARSH, David; STORKER, Gerry. Theory and methods in Political Science. 2. ed. Basingstoke et al. PalgraveMacmillan, 2002. p. 65-89.

Luiz Eduardo Peccinin - Advogado. Mestre em Direito do Estado pelo Programa de Pósgraduação em Direito da Universidade Federal do Paraná-UFPR. Especialista em Direito Administrativo pelo Instituto de Direito Romeu Felipe Bacellar. Especialista emDireito Eleitoral pela Universidade Positivo. Professor vinculado ao Centro Universitário Univel. Email: lepeccinin@gmail.com

Lygia Maria Copi - Advogada. Doutoranda no Programa de Pós-graduação em Direito da Universidade Federal do Paraná-UFPR, na área de concentração das Relações Sociaise vinculada à linha de pesquisa Novos Paradigmas do Direito. Mestra em Direito pelo mesmo Programa. Professora vinculada ao Centro Universitário Univel. E-mail: lygiama- riacopi@gmail.com. 
